\title{
Correction to: Addition of nectar sources affects a parasitoid community without improving pest suppression
}

\author{
Jacob H. Miall ${ }^{1,2} \cdot$ Paul K. Abram $^{3} \cdot$ Naomi Cappuccino $^{1} \cdot$ Andrew M. R. Bennett $^{2}$ - José L. Fernández-Triana ${ }^{2}$. \\ Gary A. P. Gibson ${ }^{4}$. Peter G. Mason ${ }^{2}$
}

Published online: 22 October 2020

○) Springer-Verlag GmbH Germany, part of Springer Nature 2020

\section{Correction to: Journal of Pest Science \\ https://doi.org/10.1007/s10340-020-01274-y}

In the original article published, the copyright line is incorrect. The correct copyright line of the article is Her Majesty the Queen in Right of Canada, as represented by the Minister of Agriculture and Agri-Food Canada

The original article has been corrected.

Publisher's Note Springer Nature remains neutral with regard to jurisdictional claims in published maps and institutional affiliations.

The original article can be found online at https://doi.org/10.1007/ s10340-020-01274-y.

Jacob H. Miall

jacob.miall@canada.ca

1 Department of Biology, Carleton University, 1125 Colonel By Drive, Ottawa, ON K1S 5B6, Canada

2 Agriculture and Agri-Food Canada, Ottawa Research and Development Centre, 960 Carling Avenue, Ottawa, ON K1A 06C, Canada

3 Agriculture and Agri-Food Canada, Agassiz Research and Development Centre, 6947 Highway 7, Agassiz, BC V0M 1A0, Canada

4 Honorary Research Associate, Agriculture and Agri-Food Canada, Ottawa Research and Development Centre, 960 Carling Avenue, Ottawa, ON K1A 06C, Canada 